
\title{
28 Research Suare \\ Effect of Concentrated growth factor (CGF) on human gingival fibroblast viability on titanium discs
}

\section{Masoumeh Faramarzi}

Tabriz University of Medical Sciences

\section{Leila Roshangar}

Tabriz University of Medical Sciences Faculty of Medicine

\section{Adileh Shirmohammadi}

Tabriz University of Medical Sciences

Mehrnoosh Sadighi ( $\square$ mehrnoosh1378@gmail.com )

Tabriz University of Medical Sciences

\section{Azadeh Madanipour}

Tabriz University of Medical Sciences

\section{Marjan Ghorbani}

Tabriz University of Medical Sciences

\section{Behnam Hashemi}

Tabriz University of Medical Sciences

\section{Research note}

Keywords: Concentrated growth factor (GCF), Human gingival fibroblast (HGF), Titaniumdisc

Posted Date: March 2nd, 2021

DOI: https://doi.org/10.21203/rs.3.rs-275034/v1

License: (c) (i) This work is licensed under a Creative Commons Attribution 4.0 International License.

Read Full License 


\section{Abstract \\ Objective}

Attachment of peri- implant mucosa to implant is crucial for long term survival of implant. Soft tissue healing around implants has been of great interest due to its important role in long-term maintenance of implant therapy. Considering the critical role of gingival fibroblasts in periodontal repair, the aim of this study was to evaluate the Concentrated Growth Factor (CGF) as an innovative approach to accelerate wound healing and increase the connective tissue seal around dental implants.

\section{Results}

$40 \%$ and $80 \%$ Concentrations of CGF significantly improved human gingival fibroblasts (HGF) viability compared to the control group ( $P$ value $=0.001)$. But the comparison of the other group with the control group was not statistically significant. The difference between $40 \%$ and $80 \%$ concentrations of CGF was not statistically significant $(P$ value $=0.061)$. Results showed that the viability of HGF treated with CGF on titanium discs(test groups 2) significantly increased as compared to the test groups 1(without CGF) at 24 hours ( $P$ value $=0.001$ ). Our results showed that $40 \%$ concentration of CGF at 24 hours significantly increased HGF viability.

\section{Introduction}

The soft tissue surrounding the transmucosal dental implant part,is called "peri-implant mucosa" and separates the periimplant bone from the oral cavity is. ${ }^{1}$ The attachment of peri-implant mucosato the implant provides a biological seal that prevents the initiation development of peri-implant diseases. ${ }^{2}$ This seal is fragile because supracrestal connective tissue attachment as seen with teeth does not exists andthe epithelial attachmentvaries inlength. ${ }^{3}$

The attachment of the soft connective tissue to the transmucosal portion of an implant is weaker than soft connective tissue attachment to the tooth root because implant does not have cementum layer that can invest the peri-implant collagen fibers. Therefore, improving the quality of the soft tissue- implant interface is considered to be of great importance. ${ }^{4}$

When bacterial or mechanicalchallenge occures, peri-implant soft connective tissues destructs in a more rapid and devastating way. ${ }^{3}$ Thus, improving the sealof the peri-implant soft tissues, especially between titanium/connective tissue interface may be an essential factor in implant survival. ${ }^{4}$

Perviouse research in the past two decades has focused on integration of dental implants to the bone while, soft tissue healing enhancement around implants has been of great attentionof due to vital role of soft tissue healing in long-term maintenance of implants. ${ }^{5}$ 
According to the previous studies, platelet concentrates have a great effect on soft tissue wound healing rather than hard tissues healing because of their release of a variety of growth factors including vascular endothelial growth factor (VEGF), platelet-derived growth factor (PDGF), and transforming growth factor-1 (TGF-1). ${ }^{6}$

The first generation of platelet concentrates was introduced in by Marx et al using platelet-rich plasma (PRP) in dentistry. They have been used widespread in many fields of dentistry, orthopaedics and esthetics for tissue regeneration becuse they are able to accerelate angiogenesis. ${ }^{7}$ Despite this, limitations in their regenerative capablity have been reported because they incorporation with anti-coagulants during preparation process known as tissue regeneration suppressors. ${ }^{8}$

CGF, first introduced by Sacco, has recently become popular. Concentrated growth factor (CGF) is an autologous leukocyte-rich and platelet-rich fibrin (L-PRF) biomaterial termed "second-generation platelet concentrate". ${ }^{9} \mathrm{CGF}$ is obtained in a solid form by centrifuging of blood samples in vacuum tubes, using a special centrifuge device similar to Choukroun's platelet rich fibrin (PRF). ${ }^{10}$ At the end of the centrifugation four fractions of blood are obtained: 1) Serum layer, 2) Second buffy coat layer, 3) Third GF and unipotent stem cell layer (CGF) 4 ( Lower red blood cell layer (RBC). ${ }^{11}$

CGF production does not require addition of other reagents while PRP needs in processing procedure. CGF itself slowly polymerizes during centrifugation just like the natural polymerization in vivo. Such polymerization is vital for proper three-dimensional (3D) organization of a fibrin mesh. ${ }^{12}$ However, a different centrifugation speed results in the formation of much larger, denser and richer GFs in fibrin matrix from CGF. ${ }^{13}$ This fibrin clot is very cohesive due to fibrinogen agglutination, factor XIII and thrombin. Factor XIIla, is activated by thrombin, makes fibrin to clot. This provides protection from degradation by plasmin, so a higher fibrin tensile strength and stability is achieved. ${ }^{14}$

Since the 3D arrangement of fibrin mesh, CGF-derived fibrin structure is favorable for cellular migration and cellular migration and gradually discharges platelet growth factors for atleast $7-10$ days. ${ }^{12} \alpha$ granules of platelets contain growth factors (PDGF), vascular endothelial growth factors (VEGF) and transforming growth factors (TGF- $\beta$ ), in conjunction with fibrinogen, fibronectin, and vitronectin. These products can modulate many phases of the healing process like the angiogenesis and

hemostasis. ${ }^{15}$ Increasing evidences address to the important role of circulating CD34 positive cells in CGF for vascular maintenance, neovascularization and angiogenesis. ${ }^{16}$

Many studies reported that platelet concentrates can an efficient adjuvants for tissue repair for surgical use. $^{15}$

Considering the critical role of gingival fibroblasts in periodontal repair, the purpose of this study was to evaluate the CGF as an innovative approach to accelerate wound healing and increase the connective tissue seal around dental implants. 


\section{Materials And Methods}

Preparation of Titanium Discs:

Commercially grade 5 titanium was processed into discs with $5 \mathrm{~mm}$ diameter and $3 \mathrm{~mm}$ thickness using the same cutting technique for all disks with a wirecut machine (ROBOFIL 310, Charmilles technologies). Disc surfaces were mechanically polished.

In all experiments, fabricated Ti substrata were cleaned in an ultrasonic device, washed three times in distilled water, left in $70 \%$ ethanol for $10 \mathrm{~min}$, and washed another five times before plating the cells.

\section{Blood Collection}

Blood samples were obtained from a healthy 28 year-old, nonsmoker Iranian woman, after obtaining her written informed consent. This study was approved by the Ethics Committee of Tabriz University of Medical Sciences.

\section{Preparation of CGF}

After obtaining a signed informed consent from three systematically healthy patient with no history of any drug use, peripheral venus blood from Brachial vein was collected and promptly centrifuged by a Medifuge centrifugation framework (Silfradent, Italy). CGF clots confined from the three blood samples were blended, set on sterile gauze to dispose of abundance serum and exchanged to fereezing tubes. CGF clots were minced, homogenized, put away at $-80^{\circ} \mathrm{C}$ for $1 \mathrm{~h}$, and after that centrifuged at $3000 \mathrm{rpm}$ for $10 \mathrm{~min}$ at room temperature. The superior liquid (CGFe) were sifted by a $0.22 \mu \mathrm{m}$ sterile syringe filter (Memberan, $\mathrm{CA}$ ) and after that put away at $-80^{\circ} \mathrm{C}$ till use. The ultimate CGFe concentrations $(5 \%, 10 \%, 20 \%, 40 \%$ and $80 \%$ ) were diluted by addingculture medium containing $10 \%$ fetal bovine serum (FBS) (Biochrom, Germany) to the CGFe.

\section{Cell Culture}

A HGF cell line (HuGu, IBRC C10459) was obtained from Iranian Biological Resource Center (IBRC, Tehran, Iran).

\section{Determine the proper concentration of CGF}

The HGF cells were seeded on a 96-well plate (SPL, South Korea) at a density of 5000 cells per well and were cultured in complete medium consisting of Dulbecco's modified Eagle's medium (DMEM)(Gibco, USA) $+10 \%$ fetal bovine serum (FBS). After 24 hours, complete medium was exchanged and different concentrations of CGF was added $(5 \%, 10 \%, 20 \%, 40 \%, 80 \%)$. Normal medium was used as the control group. After 24 hours WST-8 kit (Orangu, Cell Guidance Systems, UK) was used to analyze the cell numbers. The optical density values were measured using a microplate reader (Bio-Tek, USA) at $450 \mathrm{~nm}$. The results from different groups were compared. 


\section{Cell Viability}

The cells after passage four were seeded into 48 culture dishes (SPL, South Korea) at density of 14,000 cells per dish in complete medium consisting of Dulbecco's modified Eagle's medium (DMEM) $+10 \%$ fetal bovine serum (FBS). After 24 hours, complete medium was exchanged.

Eighteen well were set and incubated as follows: three cultures were supplemented with $10 \%$ FBS. (Negative control group), three cultures received 10\% FBS $+40 \%$ CGF (positive control group), three received Titanium Discs $+10 \%$ FBS (test group 1 ) and three received Titanium Discs $+10 \% \mathrm{FBS}+40 \%$ CGF (test group 2).

After a culture period of 24 hours, HGF viability were evaluated with WST-8.

$10 \mu \mathrm{l}$ of WST-8 solution was added to each wells and incubated for one hour; Then, Orangsolution was transferred into wells of a 96-well plate.

The optical density values were evaluated with a microplate reader use at $450 \mathrm{~nm}$.

\section{Statistical analysis}

The data are presented as mean and SD values. Differences between the control and test groups over time were tested using Mann-Whitney Utest. The level of statistical significance was set at $\mathrm{p} \llbracket 0.05$.

\section{Results}

According to our results, CGF at $40 \%$ and $80 \%$ concentrations were effective in viability of HGF cells. The cell viability at $40 \%$ and $80 \%$ concentrations of CGF was $127.85 \pm 0.6 \%$ and $135.52 \pm$

$5.1 \%$,respectively(Fig. 1).40\% and $80 \%$ Concentrations of CGF were statistically significant compared to the control group ( $P$ value $=0.001$ ). But the comparison of the other group with the control group was not statistically significant. The difference between $40 \%$ and $80 \%$ Concentrations of CGF was not statistically significant $(P$ value $=0.061)$.

For the wst-8 assay, the viability of the negative control cultures (10\% FBS) was set at $100 \%$. The mean optical density of the test groups was divided by that of the control group and reported as percentage of the control value.

According to our results, CGF treatment (positive control group) induced statistically significant (P value $=0.002)$ viability of HGF cells as compared with the negative control ( $100 \%$ viability) at 24 hours; the increase in viability was $3.28 \pm 124.6 \%$. Figure 2 showesthe effect of $40 \%$ concentrations of CGF on viability of HGF cells compared to controls at 24 hours. Data revealed that the viability of cells treated with CGF in test group 2 significantly increased as compared to the test groups 1 at 24 hours $(P$ value $=$ $0.001)$.In test groups 1 and 2 , cell viability was $3.32 \pm 61.5 \%$ and $7.5 \pm 104.79 \%$, respectively. 


\section{Discussion}

CGF is actually a fibrin plasma rich in growth factors derived from platelets which are 15.5 times more in CGF in comparison to whole blood according to Masuki et al. ${ }^{17}$ It has been reported that it quickentissue healing in numerous areas such as bone reconstruction, angiogenesis, and other types of tissue remodeling. The granules in platelets contain high concentrations of different growth factors, including TGF- $\beta 1$, PDGF-BB, FGF- $\beta$, IGF-1, VEGF, and CXCR4. ${ }^{18}$ Centrifugal technique for CGF preparation is similar to PRF with some differences resulting in a denser and longer fibrin framework with more concentrated growth factors. ${ }^{19}$ Condsidering the potency of CGF the aim of the present study was to investigate the potential role of CGF on soft tissue healing around titanium implants.

According to the literature it seems that CGF concentration plays an important role on cell viability and proliferation. According to Honda et al., CGFe with the concentrations below $10 \%$ accelerated the proliferation and maturation of human bone marrow cells. It seems this ability increased in a concentration-dependent way until $10 \%$. They also reported suppression of proliferation and maturation with $20 \%$ concentration.${ }^{12}$ The results of their study are in accordance with Masuki et al. invitro study. They also reported proliferative effects of CGFe on periosteal cells peaked at a $10 \%$ concentration and that the effects were reversed at a $20 \%$ concentration as well as promigratory effects. ${ }^{20}$ Similarly JUN et al., demonstrated CGFe at concentrations $\leq 10 \%$ promoted dental pulp cells proliferation and differentiation and promoted human umbilical vein endothelial cells proliferation, migration and vessellike structure formation. ${ }^{1}$ Qiao et al. concluded the optimum concentration was medium rather than high for human periodontal ligament cell proliferation. ${ }^{20}$ In our study, CGFe at concentrations $\geq 40 \%$ promoted cell viability in a dose dependent manner. The difference between our study and the previously above mentioned studies can be attributed to the difference in target cells. Proliferation and differentiation of various cells can be stimulated by different concentrations. The other reason may be technical differences in GCF dilution technique in different studies. However, $80 \%$ CGFe showed the same effect on HGF cell viability as $40 \%$ CGFe ( $p>0.05$ ), we perfered to use the $40 \%$ inorder not to restrict space for fibroblasts growth in culture medium.

In our study, Human gingival fibroblasts were seeded on titanium discs surfaces with and without CGF and analyzed for cell viability. CGF had a prominent influence on cell viability of HGFs. (P value $<0.05)$

According to Wang at el. more than $90 \%$ cell survival was observed on all surfaces independent of platelet processing manner. Comparing PT (pickled titanium) to SLA surface a fewer number of alive cells was present on SLA surfaces which was statistically significant. It may hence be concluded that both PRP and i-PRF illustrated fabulous cell viability and biocompatibility under in vitro circumstances. ${ }^{7}$

The high amount of growth factors in a platelet concentrate could clarify the in vitro stimulation of proliferation and viability by these preparations. Platelet concentrates have a various number of different factors with very different effects. 
As CGF is obtained by centrifuging of patient's venus blood, it is cost effective. It has a positive effect on HGF viability according to this invitro study.

\section{Conclusions}

The results from the present study demonstrate the positive effect of CGF on human gingival fibroblast cell viability when seeded on titanium discs surfaces.

\section{Limitations}

This was an invitro study. In vivo studies and even randomized controlled trials that employs a proper population size could provide useful results that would further strengthenthis study results.

\section{Abbreviations}

CGF: Concentrated Growth Factor; HGF: Human Gingival Fibroblasts;

\section{Declarations}

\section{Ethics approval and consent to participate}

The Research was performed in accordance with the Declaration of Helsinki.

The study obtained written consent from all study participants. Research ethics approval was obtained from Regional Ethic Committee of Tabriz University of Medical Sciences. Confidentiality of participants information was maintained at each level of the study.

\section{Consent for publication}

Not applicable. As this was an in vitro study, there are no details relating to an individual person.

\section{Availability of data and materials}

The datasets used and/or analysed during the current study are available from the corresponding author on reasonable request.

\section{Competing interests}

The authors declare that they have no competing interests in this section.

\section{Funding}

This research received a grant from Dental and Periodontal Research Center, Tabriz University of Medical Sciences, Tabriz, Iran. 


\section{Authors' contributions}

MF was the lead for the study, LR, ASH and MS made conceptual contributions; LR, MGH and BH designed the methodology of the work; LR and AM contributed in fibroblast culturing; MS and AM analysed the study results; AM and MF drafted the work; MS, ASH substantively revised the manuscript. All authors read and approved the final manuscript.

\section{Acknowledgements}

We are thankful to Stem Cell and Regenerative Medicine Institute of Tabriz University of Medical Sciences for the provision of HGF culturing. Thanks to Dr. Shabgard of Sahand University of Engineering Sciences and all his team members for their collaboration in providing cut titanium disks and great support during the study.

\section{References}

1. Lindhe J, Lang N. Clinical Periodontology and Implant Dentistry. In: Linhe J, Wensstrom JL, Berglundh T. The mucosa at teeth and implants. Oxford: Blackwell Munksgaard; 2015.p. 85.

2. Bates C, Marino V, Fazzalari NL, Bartold PM. Soft Tissue Attachment to Titanium Implants Coated with Growth Factors. Clin Implant Dent Relat Res. 2013;15(1):53-63.

3. Maksoud MA. Manipulation of the peri-implant tissues for better maintenance: a periodontal perspective. J Oral Implant. 2003;29:120-123.

4. Sculean A, Gruber R, Bosshardt DD. Soft tissue wound healing around teeth and dental implants. J Clin Periodontol. 2014;41 Suppl 15:S6-22.

5. Wang Y, Zhang Y, Miron RJ. Health, maintenance, and recovery of soft tissues around implants. Clin Implant Dent Relat Res .2016;18(3):618-34.

6. Miron RJ, Fujioka-Kobayashi M, Bishara M, Zhang Y, Hernandez M, Choukroun J. Platelet-Rich fibrin and soft tissue wound healing: A systematic review. Tissue Eng Part B Rev. 2017;23(1):83-99.

7. Wang X, Zhang Y, Choukroun J, Ghanaati S, Miron R. Behavior of gingival fibroblasts on titanium implant surfaces in combination with either injectable-PRF or PRP. Int J Mol Sci. 2017;18(2):331.

8. Marx RE. Platelet-rich plasma: evidence to support its use. J Oral Maxillofac Surg. 2004; 62(4):489496.

9. Dohan Ehrenfest DM, Rasmusson L, Albrektsson T. Classification of platelet concentrates: from pure platelet-rich plasma (P-PRP) to leucocyte- and platelet-rich fibrin (L-PRF). Trends Biotechnol .2009;27(3):158-167.

10. Borsani E, Bonazza V, Buffoli B, Cocchi MA, Castrezzati S, Scarì G, et al. Biological characterization and in vitro effects of human concentrated growth factor preparation: An innovative approach to tissue regeneration. Biol Med. 2015;07(05). 
11. Bozkurt Doğan Ş, Öngöz Dede F, Ballı U, Atalay EN, Durmuşlar MC. Concentrated growth factor in the treatment of adjacent multiple gingival recessions: a split-mouth randomized clinical trial. J Clin Periodontol. 2015;42(9):868-75.

12. Honda H, Tamai N, Naka N, Yoshikawa H, Myoui A. Bone tissue engineering with bone marrowderived stromal cells integrated with concentrated growth factor in Rattus norvegicus calvaria defect model. J Artif Organs. 2013;16(3):305-315.

13. Sohn, D. S., Moon, J. W., Moon, Y. S., Park J, S. \& Jung HS. The use of concentrated growth factors (CGF) for sinus augmentation. J Oral Implant Sci. 2009;38:25-38.

14. Kim T-H, Kim S-H, Sándor GK, Kim Y-D. Comparison of platelet-rich plasma (PRP), platelet-rich fibrin (PRF), and concentrated growth factor (CGF) in rabbit-skull defect healing. Arch Oral Biol. 2014;59(5):550-558.

15. Marenzi G, Riccitiello F, Tia M, di Lauro A, Sammartino G. Influence of Leukocyte- and Platelet-Rich Fibrin (L-PRF) in the Healing of Simple Postextraction Sockets: A Split-Mouth Study. Biomed Res Int. 2015;2015:1-6.

16. Majka M, Janowska-Wieczorek A, Ratajczak J, Ehrenman K, Pietrzkowski Z, Kowalska MA, et al. Numerous growth factors, cytokines, and chemokines are secreted by human CD34(+) cells, myeloblasts, erythroblasts, and megakaryoblasts and regulate normal hematopoiesis in an autocrine/paracrine manner. Blood. 2001;97(10):3075-85.

17. Masuki H, Okudera T, Watanebe T, Suzuki M, Nishiyama K, Okudera H, et al. Growth factor and proinflammatory cytokine contents in platelet-rich plasma (PRP), plasma rich in growth factors (PRGF), advanced platelet-rich fibrin (A-PRF), and concentrated growth factors (CGF). Int J Implant Dent. 2016;2(1):19.

18. Jun $H$, Lei $D$, Qifang $Y$, Yuan $X$, Deqin $Y$. Effects of concentrated growth factors on the angiogenic properties of dental pulp cells and endothelial cells: an in vitro study. Braz Oral Res. 2018;32:48.

19. Park S II, Bae H-S, Hong KS. The biological effects of concentrated growth factors on the differentiation and proliferation of human gingival fibroblasts. J Dent Hyg Sci. 2012;12(6):689-695.

20. Qiao J, An N. Effect of concentrated growth factors on function and Wnt3a expression of human periodontal ligament cells in vitro. Platelets. 2017;28(3):281-286.

\section{Figures}




\section{CONCENTRATION}

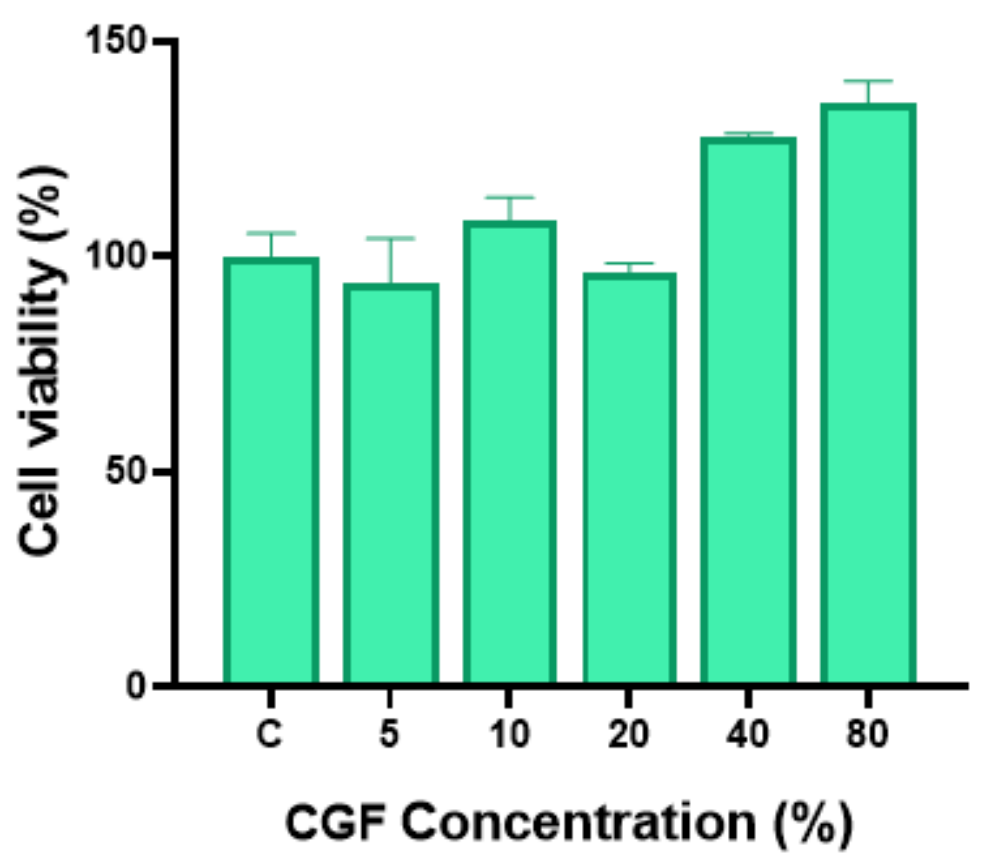

Figure 1

The effects of different concentrations of CGF on viability of HGF cells compared to controls at 24 hours. The results were calculated as the viability (percent control) compared to the negative control $(100 \%$ viability) and presented as mean \pm SD. ${ }^{*} P<0.05$

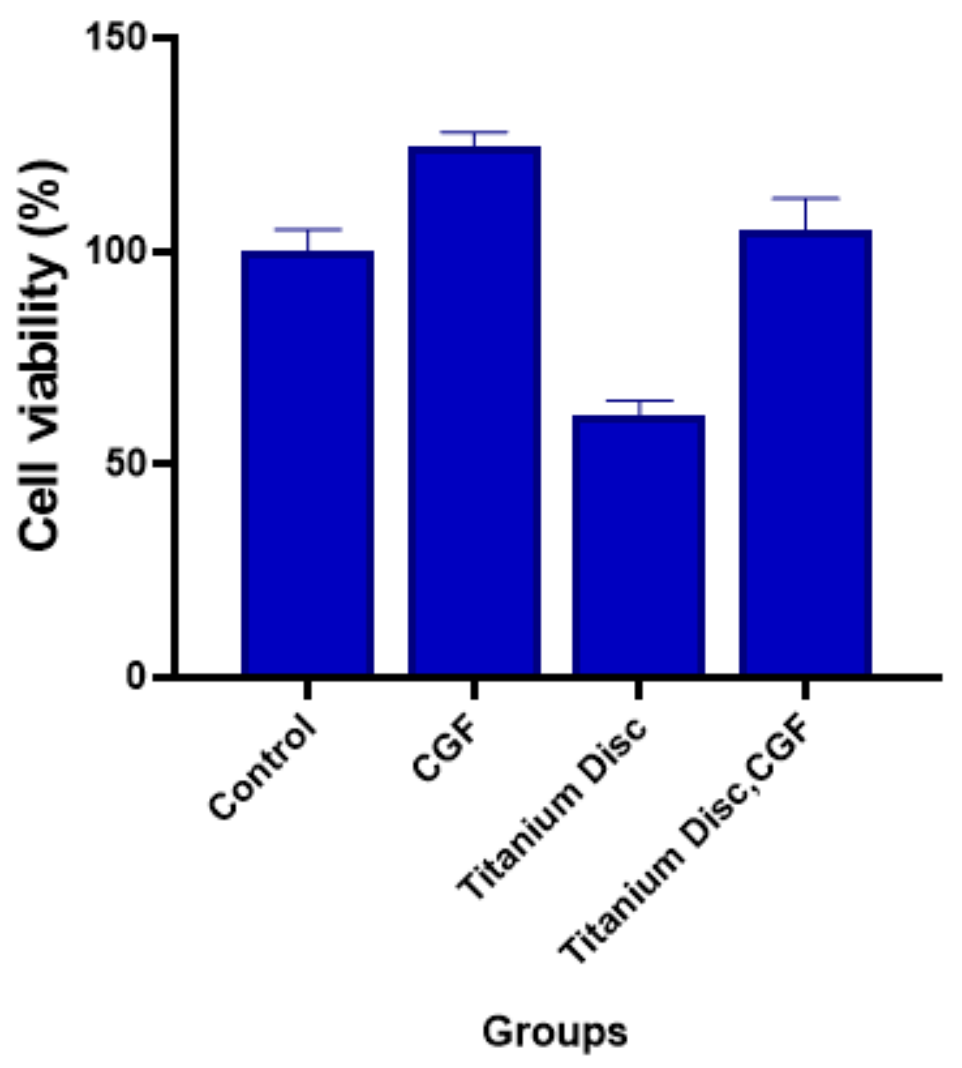


Figure 2

The effects of $40 \%$ concentrations of CGF on viability of HGF cells compared to controls at 24 hours. The results were calculated as the viability (percent control) compared to the negative control ( $100 \%$ viability) and presented as mean \pm SD. ${ }^{*} \mathrm{P}<0.05$ 